\title{
Retrospective Analysis of the Starting Dose of Combined ICS/LABA for Cough-variant Asthma and Cough-predominant Asthma
}

\author{
TAKEO NAKAJIMA ${ }^{1}$, TATSUYA NAGANO ${ }^{2}$ and YOSHIHIRO NISHIMURA ${ }^{2}$ \\ ${ }^{1}$ Nakajima Medical Clinic, Kobe, Japan; \\ ${ }^{2}$ Division of Respiratory Medicine, Department of Internal Medicine \\ Kobe University Graduate School of Medicine, Kobe, Japan
}

\begin{abstract}
Background/Aim: Although the usefulness of inhaled corticosteroids and long-acting $\beta 2$ agonists (ICS/LABA) in cough-variant asthma and coughpredominant asthma has been reported, there is no consensus on its starting dose. The aim of this study is to find the optimal dose of ICS/LABA for cough-variant asthma and cough-predominant asthma. Patients and Methods: We analysed 112 patients who visited our clinic from January 2009 to December 2012 with the chief complaint of cough that had continued for more than 3 weeks. Cough-variant asthma $(n=30)$ and cough-predominant asthma $(n=7)$ were treated with ICS/LABA. Results: There was no significant difference in cough duration time from starting ICS/LABA in cough-variant asthma and cough-predominant asthma between medium and high doses $(14.3 \%$ versus $10.9 \%$, respectively) ( $p=0.192)$. Moreover, there was no significant difference in cough duration time from starting ICS/LABA in cough-variant asthma between medium and high doses (13.2\% versus $11.5 \%$, respectively) ( $p=0.433)$. Conclusion: The medium starting dose of ICS/LABA is sufficient for treating cough-variant asthma.
\end{abstract}

Cough-variant asthma (CVA) and cough-predominant asthma (CPA) are major causes of persistent cough that continues for 3-8 weeks, and chronic cough, which continues for more

This article is freely accessible online.

Correspondence to: Tatsuya Nagano, Division of Respiratory Medicine, Department of Internal Medicine, Kobe University Graduate School of Medicine, 7-5-1 Kusunoki-cho, Chuo-ku, Kobe, 650-0017, Japan. Tel: +81 783825660, Fax: +81 783825661, e-mail: tnagano@med.kobe-u.ac.jp

Key Words: Cough, combination of inhaled corticosteroid and bronchodilator, cough variant asthma, cough predominant asthma. than 8 weeks (1). Other causes of persistent/chronic cough include allergic rhinitis, postnasal drip, gastroesophageal reflux disease (GERD), chronic obstructive pulmonary disease, atopic cough, postinfectious cough (PIC), and sinobronchial syndrome (2-10).

The chief complaint of patients with CPA is cough accompanied by wheezing. Conversely, CVA is not accompanied by wheezing. Inhaled bronchodilators are useful for diagnosing and treating CVA (11). Approximately $30-40 \%$ of patients with CVA develop typical asthma in the clinical course, and children with CVA often develop wheezing (12-14). A previously published retrospective study revealed that inhaled corticosteroids (ICSs) can decrease patients' likelihood of developing wheezing (15). However, the starting dose of ICS/long-acting $\beta 2$ agonists (LABA) has not yet been determined. Therefore, in this study, we performed a retrospective analysis of patients with CVA who were treated with ICS/LABA and compared the efficacy of medium- with high-dose ICS/LABA.

\section{Patients and Methods}

Participants. We retrospectively analysed 112 patients who visited Nakajima Medical Clinic from January 2009 to December 2012 with the chief complaint of cough that had continued for more than 3 weeks. The inclusion criteria for patients with prolonged or chronic cough were as follows: i) patients who had a cough every day and ii) patients who experienced daily life disturbance and nocturnal sleep disturbance due to cough. The exclusion criteria for patients were as follows: i) obvious abnormal findings on chest $\mathrm{X}$ ray, ii) history of asthma, iii) past or current smokers, iv) effective use of a cough suppressant, v) clear acute bronchitis/pneumonia with fever and purulent sputum, and vi) other causes of prolonged/chronic cough, such as PIC, postnasal drip, GERD, and intake of angiotensin-converting enzyme (ACE) inhibitors.

Study protocol. A total of 59 eligible patients were treated with short-acting $\beta 2$ agonists (SABA) or LABA at first, and one week later, cough was analysed. Ten patients were excluded from this 
Table I. Patient characteristics of each dose.

\begin{tabular}{lccc}
\hline & $\begin{array}{c}\text { ICS/LABA } \\
\text { medium dose } \\
(\mathrm{n}=30)\end{array}$ & $\begin{array}{c}\text { ICS/LABA } \\
\text { high dose } \\
(\mathrm{n}=7)\end{array}$ & $p$-Value \\
\hline Male/Female & $6 / 24$ & $3 / 4$ & 0.33 \\
Age, years & $39.2(16-75)$ & $28.4(17-53)$ & 0.069 \\
Cough duration & $29.2(21-84)$ & $29.0(21-56)$ & 0.98 \\
from onset to & & & \\
ICS/LABA & $12 / 18$ & $6 / 1$ & 0.042 \\
CVA/CPA & $12 / 18$ & $4 / 3$ & 0.44 \\
FBC/SFC & $3.78(2.32-6.13)$ & $4.19(3.25-5.87)$ & 0.36 \\
FVC (L) & $3.29(1.07-5.27)$ & $3.72(2.80-4.99)$ & 0.32 \\
FEV1 (L) & $83.7(67-100)$ & $89.0(85.0-95.5)$ & 0.074 \\
FEV1/FVC (\%) & $235(4-1608)$ & $284(13-729)$ & 0.75 \\
Total IgE (IU/ml) & $19 / 11$ & $5 / 2$ & 1 \\
Allergic rhinitis (yes/no) & $25 / 5$ & $7 / 0$ & 0.56 \\
Atopy (yes/no) & & & \\
\hline
\end{tabular}

ICS/LABA: Inhaled corticosteroids and long-acting $\beta 2$ agonist; CVA cough-variant asthma; CPA: cough-predominant asthma; FBC: budesonide/formoterol; SFC: salmeterol/fluticasone; FVC: forced vital capacity; FEV1: forced expiratory volume in one second.

study because of the disappearance of cough. The remaining 49 patients responded to SABA or LABA but continued to cough. These patients were diagnosed with CVA or CPA and received investigator-selected treatment. The ICS/LABA used in this study consisted of budesonide/formoterol (FBC), salmeterol/fluticasone (SFC)-dry powder inhaler (DPI), and SFC-hydrofluoroalkane (HFA) gases. The medium dose of ICS/LABA was $640 \mu \mathrm{g}$ for budesonide or $500 \mu \mathrm{g}$ for fluticasone. And the high dose of ICS/LABA was $1,280 \mu \mathrm{g}$ for budesonide or $1,000 \mu \mathrm{g}$ for fluticasone. Guidelines on inhaler usage were provided before inhalation (16).

Diagnosis of CVA and CPA. CVA was diagnosed according to the diagnostic criteria of the "Japanese Guidelines for cough, $2^{\text {nd }}$ edition" (https://www.jrs.or.jp/uploads/uploads/files/photos/1048.pdf): i) cough lasting more than 3 weeks without wheezing and ii) cough that responds to SABA or LABA. CPA was diagnosed when cough was accompanied by obvious wheezing on chest auscultation.

Statistical analysis. All statistical analyses were performed using the EZR statistical software package, version 1.37 (17). Measured values are presented as the mean \pm standard deviation (SD). Pearson's chi-square test was used to detect possible associations between the two categorical variables. Student's $t$-test was performed for the comparison of the two groups. A two-tailed $p$-value of less than 0.05 was considered significant.

\section{Results}

Study participants. Of the 49 patients who met the inclusion criteria and not the exclusion criteria, ten patients were excluded from analysis due to previous administration of oral corticosteroids, and two patients were excluded because of a single administration of ICS. The remaining 37 patients were
Table II. Patient characteristics for each device.

\begin{tabular}{lccc}
\hline & $\begin{array}{c}\text { FBC } \\
(\mathrm{n}=5)\end{array}$ & $\begin{array}{c}\text { SFC-DPI } \\
(\mathrm{n}=4)\end{array}$ & $\begin{array}{c}\text { SFC-HFA } \\
(\mathrm{n}=9)\end{array}$ \\
\hline $\begin{array}{l}\text { Male/Female } \\
\text { Age, years }\end{array}$ & $1 / 4$ & $0 / 4$ & $3 / 6$ \\
$\begin{array}{l}\text { Cough duration } \\
\text { from onset to }\end{array}$ & $43.4(21-84)$ & $21(21-21)$ & $24.1(21-28)$ \\
$\begin{array}{l}\text { ICS/LABA } \\
\text { FVC (L) }\end{array}$ & $3.14(2.58-4.13)$ & $4.72(3.92-5.33)$ & $3.6(2.81-5.43)$ \\
FEV1 (L) & $2.83(2.2-4.23)$ & $3.87(3.47-4.68)$ & $3.46(2.18-4.75)$ \\
FEV1/FVC (\%) & $80.8(74.1-86.2)$ & $82.1(74.7-88.5)$ & $87.0(81.8-95.6)$ \\
Total IgE (IU/ml) & $139(5-469)$ & $218(13-784)$ & $165(8-447)$ \\
$\begin{array}{l}\text { Allergic rhinitis } \\
\text { (yes/no) }\end{array}$ & $3 / 2$ & $3 / 1$ & $5 / 4$ \\
Atopy (yes/no) & $5 / 0$ & $3 / 1$ & $6 / 3$ \\
\hline
\end{tabular}

ICS/LABA: Inhaled corticosteroids and long-acting $\beta 2$ agonist; CVA: cough-variant asthma; CPA: cough-predominant asthma; FBC: budesonide/formoterol; SFC-DPI: salmeterol/fluticasone-dry powder inhaler; SFC-HFA: SFC-hydrofluoroalkane gases; FVC: forced vital capacity; FEV1: forced expiratory volume in one second.

included in this study. Thirty patients were treated with a medium dose of ICS/LABA, and seven patients were treated with a high dose of ICS/LABA. Table I shows the patient characteristics of each group. The patients who were treated with a medium dose of ICS/LABA were significantly accompanied with more CPA rather than with CVA $(p=0.042)$.

Starting dose of ICS/LABA. To clarify the appropriate starting dose of ICS/LABA for CVA, we compared the cough duration time following ICS/LABA treatment in CVA between medium and high doses. First, there was no significant difference in cough duration time following ICS/LABA in CVA and CPA between medium and high doses ( $14.3 \% v s .10 .9 \%$, respectively) ( $p=0.192)$ (Figure 1A). Also, there was no significant difference in cough duration time following ICS/LABA in CVA between medium and high doses (13.2\% vs. $11.5 \%$, respectively) $(p=0.433)$ (Figure 1B).

Response to ICS/LABA. In this study, the cough duration time following ICS/LABA in CVA was equivalent to that of CPA $(p=0.722)$ (Figure 2).

Optimal device for CVA. To clarify the optimal device for treating CVA, we compared the middle dose of ICS/LABA, which consisted of FBC, SFC-DPI, and SFC-HFA. The patient characteristics of these groups are summarized in Table II. Although SFC-HFA tended to be better in treating CVA compared to the other devices, there was no significant difference between the three tested devices [FBC $v s$. SFCDPI $(p=1.0)$, FBC $v s$. SFC-HFA $(p=0.44)$, and SFC-DPI $v s$. 
A

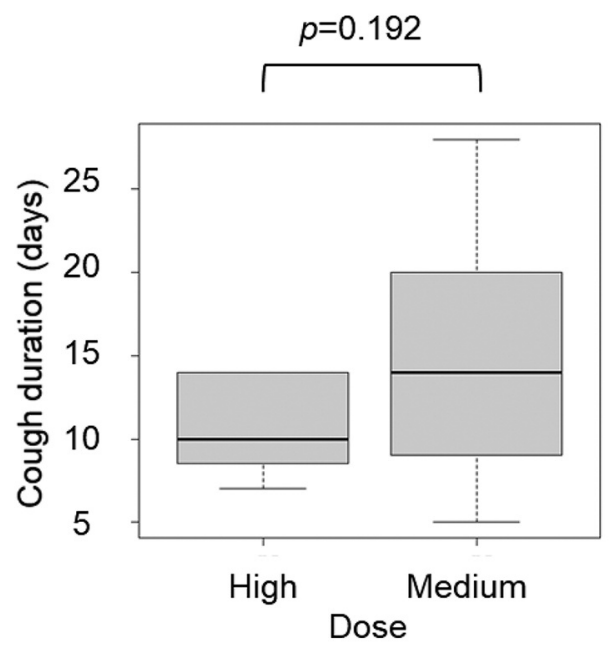

B

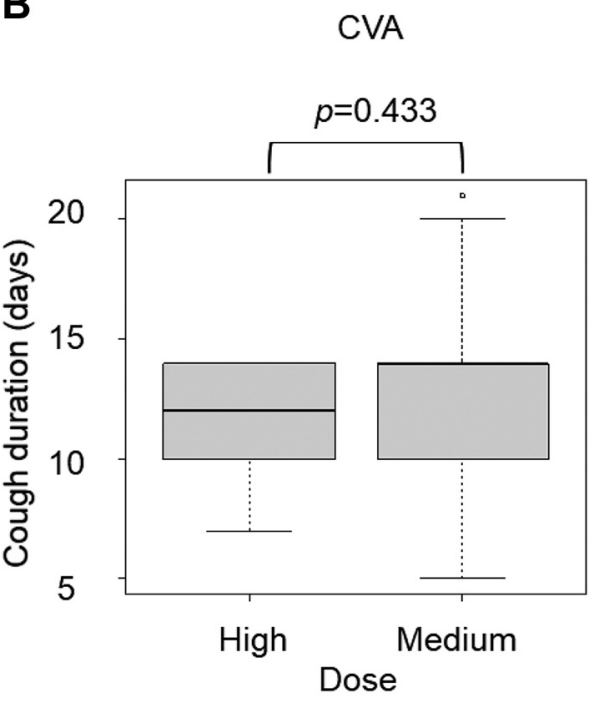

Figure 1. Duration from start of ICS/LABA to cough disappearance. There was no significant difference between the medium-dose and high-dose group in the treatment both of CVA and CPA $(p=0.192)(A)$ and of CVA $(p=0.433)(B)$. CVA: Cough variant asthma; CPA: cough-predominant asthma.

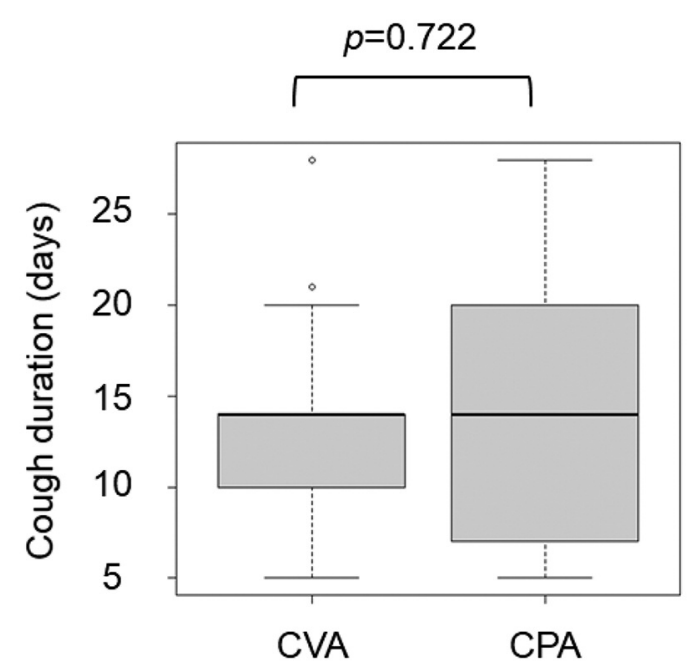

Figure 2. Response of patients in CVA or CPA to ICS/LABA treatment. There was no significant difference between the CVA group and CPA group in terms of cough duration from start of ICS/LABA to cough disappearance ( $p=0.722)$. CVA: Cough-variant asthma; CPA: coughpredominant asthma.

SFC-HFA $(p=0.29)]$ in the cough duration time from starting ICS/LABA treatment to cough disappearance (Figure 3).

\section{Discussion}

In the present study, we showed for the first time the efficacy of medium-dose ICS/LABA in comparison with high-dose ICS/LABA in the treatment of CVA. Mild asthma with less-

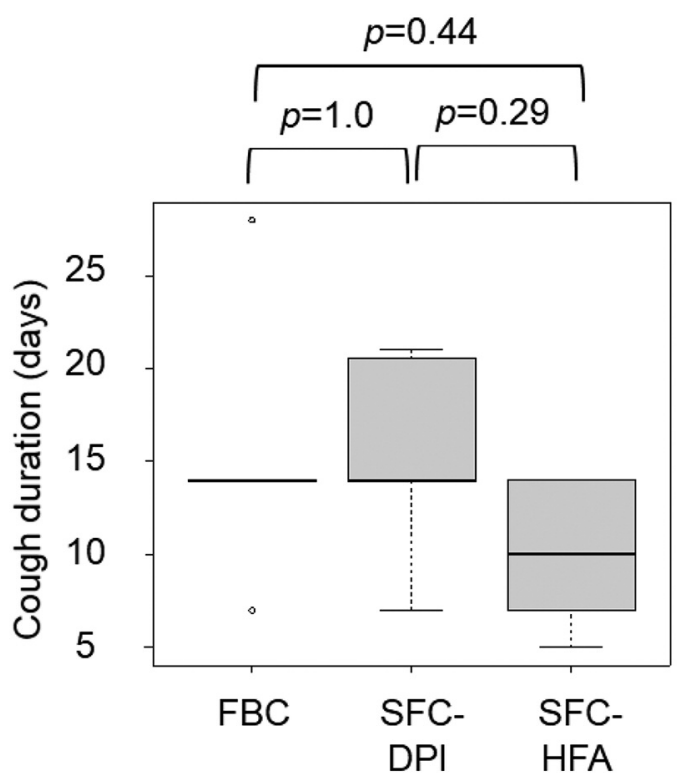

Figure 3. Optimal device for CVA treatment. CVA patients were treated with medium dose of ICS/LABA, which consisted of FBC, SFC-DPI and SFC-HFA. There was no significant difference between the three devices [FBC vs. SFC-DPI $(p=1.0), F B C$ vs. SFC-HFA $(p=0.44)$ and SFC-DPI vs. SFC-HFA $(p=0.29)]$ in cough duration time from start of ICS/LABA to cough disappearance. FBC: Budesonidelformoterol; SFC-DPI: salmeterol/ fluticasone-dry powder inhaler; SFC-HFA: SFC-hydrofluoroalkane gases.

frequent symptoms may be treated with ICS alone. There were no statistically or clinically significant differences in lung function or symptoms between the medium and high doses of ICS. 
In randomized placebo-controlled trials of ICSs in adolescents and adults with asthma, $80 \%$ of the benefit obtained at a high dose of ICSs was achieved at mild doses of ICSs and $90 \%$ at a medium dose of ICSs, respectively (18). Conversely, there are some statistically, but not clinically, significant improvements in lung function and symptoms between low and medium doses of ICSs reported in the literature (18). However, some patients with mild to moderate asthma may choose to discontinue treatment due to the lack of a sufficient and immediate therapeutic effect when they are treated with ICS alone.

Notably, we found that it seems to be important to improve symptoms using bronchodilators as well as antiinflammatory treatment at an early stage. Indeed, mediumdose ICS/LABA can significantly improve early morning peak flow as well as airway hypersensitivity, and it is comparable to ICSs alone in terms of safety (19-23).

In the present study, we also showed that HFA devices tend to be more effective compared to DPI devices. So far, it is unclear whether cough reduces patients' inhalation power.

The limitation of this study is that the selection bias was inevitable, although investigators arbitrarily allocated patients to medium- or high-dose groups.

In conclusion, we showed that a medium dose of ICS/LABA was compatible with high doses of ICS/LABA for the treatment of CVA. A medium dose of ICS/LABA may be a possible candidate for CVA therapy.

\section{Conflicts of Interest}

The Authors state that they have no conflicts of interest related to this study.

\section{Authors' Contributions}

TakN and TatN drafted the manuscript; TakN developed the database; TakN and $\mathrm{YN}$ conceived the study design; TatN conducted the statistical analyses. All Authors analysed the data, conceived the study, read and approved the final manuscript.

\section{Acknowledgements}

We sincerely thank all the study participants. We would like to thank Editage (www.editage.com) for English language editing.

\section{References}

1 Otoshi T, Nagano T, Funada Y, Takenaka K, Nakata H, Ohnishi H, Nishiuma T, Nakajima T, Kageshita T, Tsuchiya T, Yamamoto M, Kobayashi K and Nishimura Y: A Cross-sectional survey of the clinical manifestations and underlying illness of cough. In Vivo 33(2): 543-549, 2019. PMID: 30804139. DOI: 10.21873/invivo.11508

2 Poe RH, Harder RV, Israel RH and Kallay MC: Chronic persistent cough. Experience in diagnosis and outcome using an anatomic diagnostic protocol. Chest 95(4): 723-728, 1989. PMID: 2924600. DOI: 10.1378/chest.95.4.723
3 O'Connell F, Thomas VE, Pride NB and Fuller RW: Capsaicin cough sensitivity decreases with successful treatment of chronic cough. Am J Respir Crit Care Med 150(2): 374-380, 1994. PMID: 8049818. DOI: 10.1164/ajrccm.150.2.8049818

4 Niimi A, Nguyen LT, Usmani O, Mann B and Chung KF: Reduced $\mathrm{pH}$ and chloride levels in exhaled breath condensate of patients with chronic cough. Thorax 59(7): 608-612, 2004. PMID: 15223872. DOI: 10.1136/thx.2003.012906

5 Fujimura M, Abo M, Ogawa H, Nishi K, Kibe Y, Hirose T, Nakatsumi Y and Iwasa K: Importance of atopic cough, cough variant asthma and sinobronchial syndrome as causes of chronic cough in the Hokuriku area of Japan. Respirology 10(2): 201-207, 2005. PMID: 15823186. DOI: 10.1111/j.1440-1843.2005.00686.x

6 Matsumoto H, Niimi A, Takemura M, Ueda T, Yamaguchi M, Matsuoka H, Jinnai M, Chin K and Mishima M: Prevalence and clinical manifestations of gastro-oesophageal reflux-associated chronic cough in the Japanese population. Cough 3: 1, 2007. PMID: 17210085. DOI: 10.1186/1745-9974-3-1

7 Yamasaki A, Hanaki K, Tomita K, Watanabe M, Hasagawa Y, Okazaki R, Yamamura M, Fukutani K, Sugimoto Y, Kato K, Kodani M, Ikeda T, Konishi T, Kawasaki Y, Tokuyasu H, Yajima $\mathrm{H}$, Sejima $\mathrm{H}$, Isobe $\mathrm{T}$ and Shimizu E: Cough and asthma diagnosis: physicians' diagnosis and treatment of patients complaining of acute, subacute and chronic cough in rural areas of Japan. Int J Gen Med 3: 101-107, 2010. PMID: 20463827. DOI: $10.2147 /$ ijgm.s8167

8 Niimi A, Ohbayashi H, Sagara H, Yamauchi K, Akiyama K, Takahashi K, Inoue H, Wakayama T, Kobayashi H, Hasegawa M, Kimura G, Yokoe T and Adachi M: Cough variant and cough-predominant asthma are major causes of persistent cough: a multicenter study in Japan. J Asthma 50(9): 932-937, 2013. PMID: 23841529. DOI: 10.3109/02770903.2013.823444

9 Dąbrowska M, Grabczak EM, Arcimowicz M, DomerackaKołodziej A, Domagała-Kulawik J, Krenke R, MaskeyWarzęchowska M, Tarchalska B and Chazan R: Causes of chronic cough in non-smoking patients. Adv Exp Med Biol 873: 25-33, 2015. PMID: 26285610. DOI: 10.1007/5584_2015_153

10 Watanabe K, Shinkai M, Shinoda M, Hara Y, Yamaguchi N, Rubin BK, Ishigatsubo $\mathrm{Y}$ and Kaneko T: Measurement of eNO with portable analyser might improve the management of persistent cough at primary care practice in Japan. Clin Respir J 10(3): 380-388, 2016. PMID: 25307553. DOI: 10.1111/crj.12228

11 Irwin RS, French CT, Smyrnios NA and Curley FJ: Interpretation of positive results of a methacholine inhalation challenge and 1 week of inhaled bronchodilator use in diagnosing and treating cough-variant asthma. Arch Intern Med 157(17): 1981-1987, 1997. PMID: 9308510.

12 Spector SL and Tan RA: Effectiveness of montelukast in the treatment of cough variant asthma. Ann Allergy Asthma Immunol 93(3): 232-236, 2004. PMID: 15478381. DOI: 10.1016/S1081-1206(10)61493-7

13 Fujimura M, Ogawa H, Nishizawa Y and Nishi K: Comparison of atopic cough with cough variant asthma: is atopic cough a precursor of asthma? Thorax 58(1): 14-18, 2003. PMID: 12511712. DOI: $10.1136 /$ thorax.58.1.14

14 Nakajima T, Nishimura Y, Nishiuma T, Kotani Y, Funada Y, Nakata $\mathrm{H}$ and Yokoyama M: Characteristics of patients with chronic cough who developed classic asthma during the course of cough variant asthma: a longitudinal study. Respiration 72(6): 606-611, 2005. PMID: 16113512. DOI: 10.1159/000087459 
15 Matsumoto $\mathrm{H}$, Niimi A, Takemura $\mathrm{M}$, Ueda $\mathrm{T}$, Tabuena $\mathrm{R}$, Yamaguchi M, Matsuoka H, Hirai T, Muro S, Ito Y, Mio T, Chin $\mathrm{K}$, Nishiyama $\mathrm{H}$ and Mishima M: Prognosis of cough variant asthma: a retrospective analysis. J Asthma 43(2): 131-135, 2006 PMID: 16517429. DOI: 10.1080/02770900500498477

16 Katsurada M, Nagano T, Nakajima T, Yasuda Y, Miwa N, Sekiya R, Kobayashi K, Hojo D and Nishimura Y: Retrospective analysis of the effect of inhaler education on improvements in inhaler usage. Respir Investig 59(3): 312-319, 2021. PMID: 33899742. DOI: 10.1016/j.resinv.2020.09.008

17 Kanda Y: Investigation of the freely available easy-to-use software 'EZR' for medical statistics. Bone Marrow Transplant 48(3): 452458, 2013. PMID: 23208313. DOI: 10.1038/bmt.2012.244

18 Beasley R, Harper J, Bird G, Maijers I, Weatherall M and Pavord ID: Inhaled corticosteroid therapy in adult asthma. Time for a new therapeutic dose terminology. Am J Respir Crit Care Med 199(12): 1471-1477, 2019. PMID: 30645143. DOI: $10.1164 / \mathrm{rccm} .201810-1868 \mathrm{CI}$

19 Zetterström O, Buhl R, Mellem H, Perpiñá M, Hedman J, O'Neill $S$ and Ekström T: Improved asthma control with budesonide/formoterol in a single inhaler, compared with budesonide alone. Eur Respir J 18(2): 262-268, 2001. PMID: 11529282. DOI: 10.1183/09031936.01.00065801

20 Kavuru M, Melamed J, Gross G, Laforce C, House K, Prillaman B, Baitinger L, Woodring A and Shah T: Salmeterol and fluticasone propionate combined in a new powder inhalation device for the treatment of asthma: a randomized, double-blind, placebocontrolled trial. J Allergy Clin Immunol 105(6 Pt 1): 1108-1116, 2000. PMID: 10856143. DOI: 10.1067/mai.2000.105711
21 Lundbäck B, Rönmark E, Lindberg A, Jonsson AC, Larsson LG, Pétavy $\mathrm{F}$ and James M: Control of mild to moderate asthma over 1-year with the combination of salmeterol and fluticasone propionate. Respir Med 100(1): 2-10, 2006. PMID: 16243498. DOI: $10.1016 /$ j.rmed.2005.09.006

22 Kelly MM, O'Connor TM, Leigh R, Otis J, Gwozd C, Gauvreau GM, Gauldie J and O'Byrne PM: Effects of budesonide and formoterol on allergen-induced airway responses, inflammation, and airway remodeling in asthma. J Allergy Clin Immunol 125(2): 349-356.e13, 2010. PMID: 19969339. DOI: 10.1016/ j.jaci.2009.09.011

23 Janjua S, Schmidt S, Ferrer M and Cates CJ: Inhaled steroids with and without regular formoterol for asthma: serious adverse events. Cochrane Database Syst Rev 9: CD006924, 2019. PMID: 31553802. DOI: 10.1002/14651858.CD006924.pub4
Received December 11, 2021

Revised January 24, 2022

Accepted January 25, 2022 